Biological Techniques Series

Microelectrode Methods for Intracellular Recording and lonophoresis

\title{
R.D. Purves
}

Mav 1981, $x+146 p p .$, E9.80 (UK on/v) $/ \$ 24.00,0.12 .567950 .5$

This book deals with the use of glass microelectrodes for measurement of cellular potentials and micro-application of drugs. The newcomer will find a wealth of practical advice on the choice of apparatus, making and filling electrodes, impalement of cells, and prevention of electrical or mechanical interference.

\section{Biological Microcalorimetry}

\section{edited by A.E. Beezer}

1980, $x+484 p p .$, f33.00 (UK only) / $\$ 79.50,0.12 .083550 .9$

Biological Microcalorimetry is an up-to-date account of microcalorimetry as applied to biological topics and gives a comprehensive review of this growing area of research. For noncalorimetrists it is intended as an introduction and for those already involved in calorimetry it provides a survey of other important biological studies. The topics covered range from 'pure' model biochemical systems to complex, intact biological systems such as blood.

\section{A Subsidiary of Harcourt Brace Jovanovich, Publishers Academic AP Press 24-28 Oval Road, London NW1 7DX, England 111 Fifth Avenue, New York, NY 10003, USA}




\section{INFORMATION FOR CONTRIBUTORS TO}

\section{QUARTERLY REVIEWS OF BIOPHYSICS}

I. Quarterly Reviews of Biophysics is the official journal of the International Union for Pure and Applied Biophysics. As such, its primary aim is to provide a forum for general and specialized communication between biophysicists working in different areas. This will normally be achieved by inviting authors who have made significant contributions to give a critical and readable account of recent progress in their special fields. Shorter and even controversial articles discussing topics of particular current interest will also be published.

2. Reviews should preferably be written in English. The style of presentation must be concise, with only key references.

3. Three copies of manuscripts are required. They should be typed in double spacing with a margin of $4 \mathrm{~cm}$ all round. The position of tables and illustrations should be indicated in the text. Tables and legends for illustrations should be typed on separate pages. A table of contents should be provided for printing at the head of the article.

4. In the text, the references should be to authors and year. When a paper cited has three or more authors the style Smith et al. (1973) should be used on all occasions. At the end of the paper, references should be listed alphabetically, with the full title of each paper, and the first and last pages. Abbreviations of journal titles should follow the latest edition of the World List of Scientific Periodicals. For example

Bernal, J. D. (1967). Origin of Life. London: Weidenfeld and Nicolson. EIGEN, M. (1968). New looks and outlooks on physical enzymology. $Q$. Rev. Biophys. 1, 3-33.

5. Drawings should be in Indian ink on tracing paper. They should be drawn roughly twice the size of the finished block. Explanations should as far as possible be placed in the legends. Lettering for photographs should either be on a duplicate print or on an accurately registered overlay.

6. The author will receive only one set of page proofs for correction. Fifty reprints of each review will be provided free of charge. Additional copies may be purchased. 


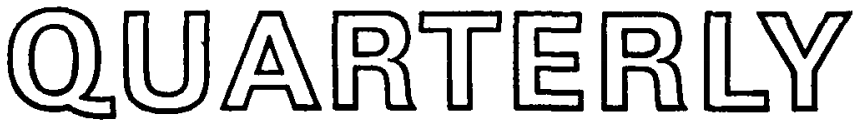 REVREWS (0) BUOPIYSICS}

Reviews on the following topics will appear in forthcoming issues: Can Free Energy Transduction be localized at some crucial part of the Enzymatic Cycle?

Terrell L. HiLl and Evan Eisenburg

Magnetic field effects on photosynthetic reactions

A. J. HoF F

Relaxation studies of ion transport systems in lipid bilayer membranes

P. Lauger, R. Benz, G. Stark, E. Bamberg, P. C. Jordan, A. FAHR and W. Brock

(C) Cambridge University Press 198I

CAMBRIDGE UNIVERSITY PRESS

The Pitt Building, Trumpington Street, Cambridge CB2 IRP 32 East 57th Street, New York, NY 10022 